\title{
THE UNRELIABILITY OF BLOOD TYPING AGED BONE
}

\author{
FREDERICK P. THIEME AND CHARLOTTE M. OTTEN \\ University of Michigan \\ INTRODUCTION
}

When Boyd and Boyd ('33) and Candela ('36) first demonstrated the possibility of the $\mathrm{ABO}$ blood typing of aged human bone and tissues, anthropologists were quick to realize the potential value of such data for historical studies of human populations. It was, in fact, this appealing potential which encouraged the profession to have greater faith in the reliability of such tests than was actually warranted.

Boyd and Boyd ('39), using 14 known autopsy samples up to five years old, achieved typing results which they called "encouraging but not as conclusive as would be wished for unknown material"' (p. 424). When Candela ('40) successfully typed a portion of their material, doubts were somewhat relieved. But an element of uncertainty remains. In the first place, the growing literature of serological research leads to a conception of the blood group ABO polysaccharide-polypeptide antigens as substances immensely stable under some conditions, but contrastingly fragile under others.

In the second place, the method employed in bone typing is not sufficiently exact or specific to meet the requirements of the problem. The several shortcomings of this method will be discussed below.

When the Laboratory of Physical Anthropology was first set up at the University of Michigan under sponsorship of the Wenner-Gren Foundation, we secured over 40 bone samples from individuals of known blood type at autopsy. These have been tested after aging by means of the standard inhibition 
test. Blood stains of known type were similarly tested after aging and drying. The role of bacterial enzymes in the disintegration of blood group antigens was next investigated. Thus our work reported here falls into three sections: Bone Typing, Stain Typing, and the Action of Bacterial Enzymes on Blood Group Antigens.

\section{METHODS, TFCHNIQUES AND RESULTS}

The test procedure used in the typing of aged bone is a crucial factor in determining the reliability of the results. For this reason it is necessary to describe the test and its limitations before the results of our studies can be evaluated.

The inhibition test depends upon the reduction in titer of known antisera by the inhibiting action of specific antigens. The reduction in titer is, in turn, detected by the differential agglutination of appropriate red cells added to the antisera. However, such titer reduction may occur for reasons other than by combination with specific antigens. Deterioration of the antisera without regard to the presence of antigen may occur during the test period and may proceed at unequal rates. In spite of refrigeration and the addition of bactericides such may well be the case with polluted material. The notorious instability of antibodies makes both differential and absolute deterioration by contaminants possible in the absence of specific antigens over the period in which the antibody inhibition progresses. That such bacterial products may reduce antibody titer without reference to antigens present will be demonstrated below.

Another source of test error is from non-specific absorption which apparently is due to the inorganic and physical properties of the material tested. Particle size is probably the most important factor and we have shown (Thieme, et al., '56) that such serologically inert materials as charcoal, kaoline and benzonite can cause very significant antibody titer reduction. The great variability in the nature of decomposing bone, as we shall see, can make for differences in absorption so that it may progress at a different rate and to a different degree, 
say, in the case of bone samples which are originally pasty, friable or fairly compact before being ground for testing. Using agglutinins of identical titer, bone of extremely fine particle size will presumably lower the titer significantly more than larger ones without regard to the blood type.

Other hazards of testing lie in the ubiquitous distribution of substances closely resembling blood group antigens in the animal and plant world which can act as contaminants and give false inhibition reactions. Salazar Mallen ('51), for instance reports that the soil surrounding specimens from Monte Alban gave A type reactions similar to that of the skeletal material tested. Some bacterial polysaccharide components themselves closely resemble blood group antigens and very specific tests would be necessary to detect such contaminants. Another matter of concern is the observation that powdered bone loses its antigenic reactivity shortly after fine grinding, unless sealed in vacuum containers. The consistency and porosity of bone itself apparently has a bearing on antigen retention. Furthermore, cancellous bone and spongy bone are probably different in this respect as well as in their original antigen content.

\section{Bone typing}

Over 40 autopsy samples, mostly lumbar vertebrae, were buried in stone jars in sandy soil, and aged from 2 to 3 years. Blood type was determined from heart blood recovered from each individual at autopsy, and secretor status from a sample of bile, according to a modification of Boyd's secretor test for saliva. The accuracy of our bile test was checked by procuring both saliva and bile samples from cholecystectomy patients at the University of Michigan hospital. Comparisons showed the secretor test on bile to be completely reliable.

Nineteen individual bone specimens were typed by the standard inhibition technique. All the $B$ and $A B$ specimens were used and the seven $O$ and eight $A$ were selected from the total of these types. The selection was made of those which were 
most completely decomposed and free from residual fat. Many of the other specimens contained a large amount of fat which makes typing practically impossible with standard test methods. Both immune antisera and alpha and beta isoagglutinins were used, of titers of $1: 8,1: 16$ and $1: 32$ respectively. Thus each ground bone specimen was subjected to twelve individual testings, involving three dilutions each of the four antisera. Pooled AB sera was the diluent used in order to maintain constant density and thus better equalize physical factors, including those relating to the phenomenon of nonspecific absorption. Hemolysis caused some difficulty in reading the tests, but was partially overcome by increasing surface tension by raising salt concentration, adjustment of $\mathrm{pH}$, or by using higher-titered antisera $(1: 128)$ which gave faster differential readings. The latter step is admittedly a risky procedure, and advisable only in combination with more traditional techniques.

The typing results are recorded in table 1 . Since by this an $O$ cannot be distinguished from a total loss of antigen, the $A$, $B$ and $A B$ most reliably indicate the degree of success in antigen recovery and specificity. Of the 12 specimens not type $O$, only 4 tested as expected giving an error rate of 75 per cent. We do not know whether the errors were due to the destruction of the A and/or B antigens, or whether they have been transformed to $O$. Some more sensitive technique will have to be employed in such cases to indicate the presence of $\mathrm{O}$ antigen since so called "anti-O" sera made from absorbed cattle sera, Ulex europeus extract, or chicken antisera appears to be unsatisfactory for the purpose of indicating $O$ antigen in old bone using this test method.

The appearance of the vertebrae upon exhumation presented great variation, ranging from a chalky, gray, friable consistency throughout with visible mold mycelia and little odor, to a dark brown pasty rancid-smelling interior. We also found intermediate shades of brown and tan, and intermediate putrifactive odors and textures. We found that the dark brown ran- 


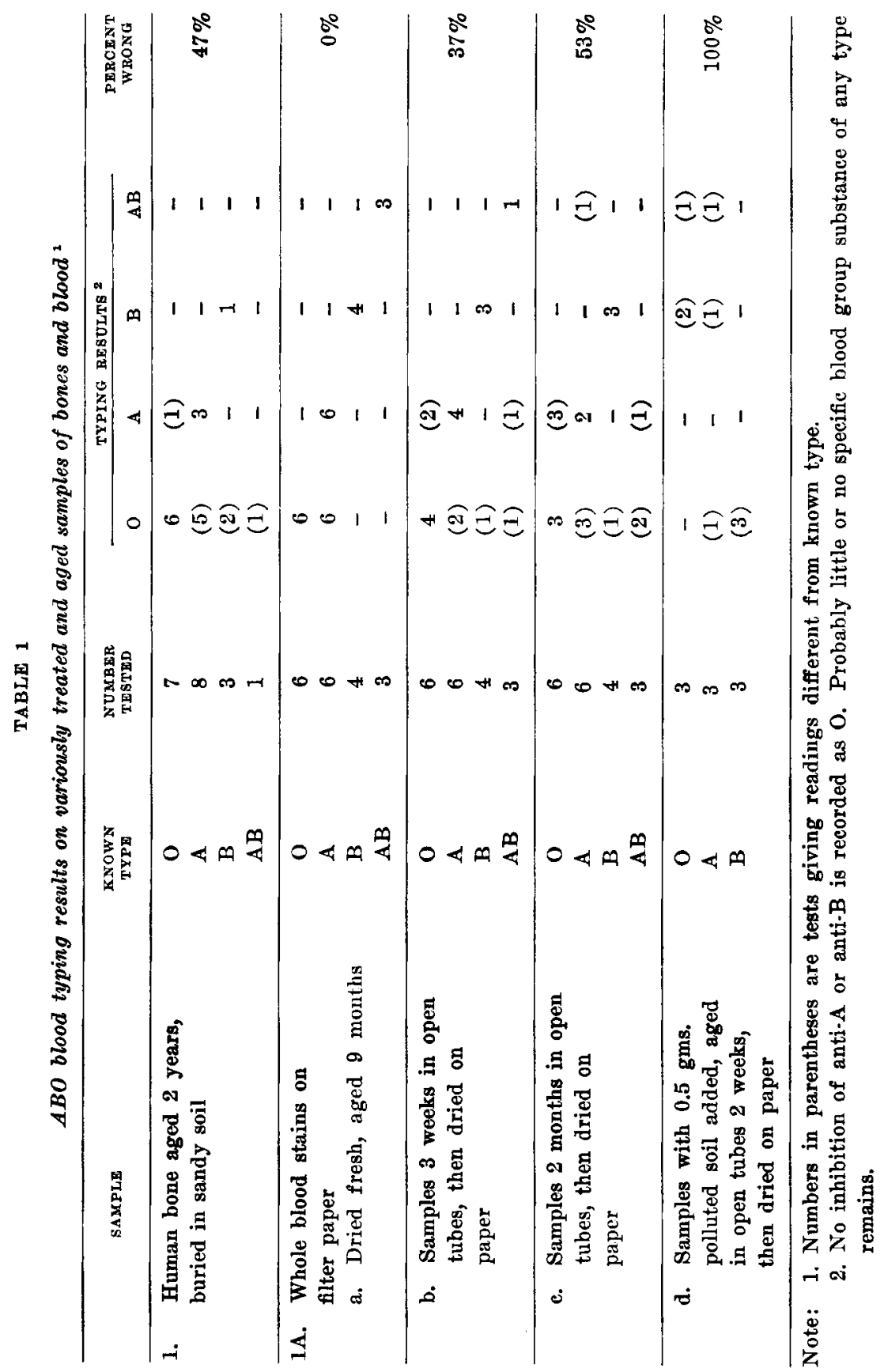


cid types of decomposition presented the greatest problems in typing, and least of ten gave satisfactory results.

These varying characteristics must be ascribed to the action of different organisms possibly already present in the tissue at the time of burial and/or in the soil. The samples were buried at different times over the period of a year and the soil used was not identical although it came from the same location. The unreliability of the results seems to implicate bacterial action.

\section{Stain typing}

Stains made from fresh blood of known type and dried upon filter paper have continued to give completely accurate readings after aging at room temperature for nine months. However, blood allowed to putrify in open tubes at room temperature three weeks before drying gave $37 \%$ error. When kept eight weeks before drying, the error was 53\% (see table 1 ). These results are in substantial agreement with the work of Gettler and Kramer ('36) and the unreliability seems clearly to increase as bacterial action is more prolonged.

To obtain maximum decomposition a gram of manure-laden soil was added to each of three tubes of fresh $O$ and $A$ and $B$ type blood which was then used to make stains after two weeks of putrifaction. Not one of these tested accurately. In examining our results, one might be led to speculate whether a transformation of one type of antigen to another had taken place. Unfortunately the inhibition test cannot now be relied upon to test for the presence of $\mathrm{O}$ antigens due to the absence of a specific human anti-O. As apparent transformations are mainly from $\mathrm{A}$ and/or $\mathrm{B}$ to $\mathrm{O}$, their testing must be done more exactly and specifically than is possible with the inhibition procedure.

\section{Action of bacterial enzymes on blood group antigens}

Workers for over two decades, including Stack and Morgan ('49) Schiff, ('35, '39) and Iseki and his colleagues, ('51, '52, '53, '55, '56) have shown that certain bacterial enzymes may 
act to decompose not only the blood group antigens but the structurally-related pneumococcus carbohydrates as well. Over a dozen such organisms have been named to date, most of which may occur naturally in soil, fecal material or decaying animal or vegetable matter. They are, in general, at least facultative anaerobes, sacchrolytic in action, and thus ideal candidates to be held accountable under some conditions for the decomposition of antigens in aged skeletal material.

About half of these organisms have been found to attack the $A$ antigen; one attacks $B$; the rest deteriorate various constellations of antigens, with some strains effecting a complete deterioration of all $\mathrm{ABO}(\mathrm{H})$ blood group substances. Iseki and his colleagues, in a recent series of articles ('51, '52, '53, '55, '56), have claimed not only antigenic deterioration, but transformation from one blood group into another. This work may be summarized as follows :

1. An enzyme which decomposes $\mathrm{A}$, but not $\mathrm{B}$ or $\mathrm{O}(\mathrm{H})$ was obtained from Clostridium tertium.

2. A heat labile (5 minutes at $60^{\circ} \mathrm{C}$.) enzyme decomposing $\mathrm{O}$, but not $\mathrm{A}$ or $\mathrm{B}$ obtained from Bacillus fulminans.

3. An enzyme which decreases A substance, and increases $O$, in A secretor saliva and thus appears to transform A into $O$ was obtained from Clostridium tertium (as in 1 , above).

4. The enzyme of Bacillus fulminans decomposes T substance (probably $\mathrm{Le}^{\mathrm{a}}$ ) found in $\mathrm{ABO}$ non-secretor saliva.

5. The changes in type are ascribed to separation of fucose from the group substance.

6. Using an enzyme produced by Bacillus cereus, B substance was tranformed into $\mathrm{O}(\mathrm{H})$.

These studies conclude that specific group substances can be selectively destroyed by enzymatic action and that $\mathrm{A}$ and $\mathrm{B}$ can be transformed into $\mathrm{O}(\mathrm{H})$.

In repeating certain relevant aspects of former work, the enzyme of Clostridia perfringens, the soil organism most frequently associated with gas gangrene infections, was used in 
testing. Culture filtrates of three other Clostridia species, novyi, sporogenes, and septicum were used as controls. The action of culture filtrates of the four species were studied in relation to commercial blood group antigens, antigens in secretor saliva, and erythrocytes. The destruction of A substance prepared from hog gastric mucin, and in human saliva after 24 hours exposure, was verified in the case of perfringens; there was no such effect from the control enzymes. Thus, we have verified that closely related enzymes may behave differently.

In all cases the bacterial filtrates from known strains were prepared from 24-hour cultures grown anaerobically in fluid thioglycollate medium (Difco), centrifuged at high speed, and run through a Seitz filter.

$\mathrm{A}, \mathrm{B}$ and $\mathrm{O}$ secretor saliva as well as commercial $\mathrm{A}$ and $\mathrm{B}$ antigens prepared from hog gastric mucin were set up in dilutions of $1: 10,1: 50,1: 100$ and $1: 200$. A mixture of the bacterial enzyme-filtrate and neutral phosphate buffer were used in equal parts for diluent. Controls were prepared in two lots : without the addition of antigens, and without the enzyme, which was replaced by saline. After 24 hours, all samples were tested for the presence of antigen by means of the inhibition test. Commercial A antigen appeared entirely destroyed by perfringens enzyme, while $B$ was unchanged. In the case of secretor saliva, there was either total destruction of $A$, or, in one case, an almost complete reduction of $\mathrm{A}$ except for a small amount which persisted to lower the titer of Ulex by one tube. There is also the possibility here of a partial transformation from $\mathrm{A}$ into $\mathrm{O}$, as claimed for Clostridium tertium by Iseki. However, until a successful specific anti-O as against an anti$\mathrm{H}$ indicator (such as Ulex) is developed, we cannot demonstrate conclusively the transformation of secretor antigens from one blood group into another.

A further complication is presented by the agglutinating behavior of erythrocytes exposed to dilute and buffered perfringens enzyme. Group A cells, upon exposure, demonstrate a panagglutination toward all antisera, especially strongly 
affected by Ulex extract. Cells of all blood groups, in fact, react more strongly to Ulex after even a few hours of exposure to the enzyme, or perhaps even in the course of the inhibition testing itself.

Our perfringens organism, unlike one of the strains tested by Stack and Morgan ('49), did not destroy the B antigen. The B secretor antigen was, as we noted, apparently untouched, but the anti-H component as indicated by Ulex, either was somewhat reduced in amount, or the cells used as indicators were differentially agglutinated due to enzymatic influence.

Parenthetically, it is of interest to note that another enzyme elaborated by the perfringens organism, known as collagenase, is capable of collagen destruction, and may thus modify the structure and consistency of bone and further the entrance of the antigen-destroying enzyme.

\section{CONCLUSIONS}

The accuracy of bone typing is seen to rest upon the amount and chemical integrity of antigenic remains in bone, undestroyed and untransformed by bacterial enzymes, and upon the reliability and specificity of indicator tests. The inhibition test has been seen to offer numerous potentialities for error in unequal or total destruction of test antisera by contaminants present, in unequal non-specific absorption leading to false interpretations, the presence of adventitious antigenic elements which cannot be distinguished from blood group substances, and the possibility of the influence of bacterial enzymes upon the test-cells themselves.

The secretor status of the individual tested was not found to relate to the accuracy of bone typing.

In conclusion, results obtained in the typing of aged bone or stains by the inhibition test do not appear reliable under some conditions. It is likely that material such as the Aleut bone typed by Candela ('39), mummified tissue typed by the Boyds ('37), and such dessicated and/or naturally refrigerated material, not in contact with damp soil, is accurate, or enough so to use with security in historical studies. 
The further efficiency of bone typing will rest upon renewed attempts to find antigen-specific indicators, possibly such as paper chromatography or precipitin testing, which will eliminate the many disadvantages of antibody inhibition.

\section{ACKNOWLEDGMENT}

This research was carried out with funds received from the Q.M. Research and Development Command under Project 7-64-12-004C.

\section{LITERATURE CITED}

Boyd, W. C. 1933 Blood grouping by means of preserved musele. Science, 78: 578.

1939 Blood grouping reactions of preserved bone and muscle. Amer. J. Phys. Anthrop., 25: 421-434.

Boyd, W. C., AND L. G. Boyd 1934a Group specificity of dried muscle and saliva. J. Immunology, 26: 489-494.

1934b An attempt to determine the blood groups of mummies. Proc. Soc. Exp. Biol. and Med., 31: 671-674.

1937a Blood grouping in forensic medicine. J. Immunology, sz: 159-172.

1937b Blood grouping tests on 300 mummies, with notes on the precipitin test. J. Immunology, 32: 307-319.

CANdela, P. B. 1936 Blood group reactions in ancient human skeletons. Am. J. Phys. Anthrop., 21: 429-432.

1937 Blood group determinations upon Minnesota and New York skeletal material. Am. J. Phys. Anthrop., 23: 71-78.

1939a Blood group determination upon the bones of thirty Aleutian mummies. Am. J. Phys. Anthrop., 24: 361-383.

$1939 \mathrm{~b}$ Blood tests on stains, mummified tissue, and eancellous bone. Am. J. Phys. Anthrop., 25: 187-214.

1940 Reliability of blood tests on bones. Am. J. Phys. Anthrop., g7: $367-381$.

Gettler, A. O., AND H. E. Kramer 1936 Blood grouping in forensic medicine. J. Immunology, 31: 321-329.

ISEKI, S., AND S. OKADA 1951 On a specifie enzyme which decomposes A substance. Proc. Japan. Acad., 27: 455-458.

ISEKI, S., AND S. TSUNODA 1952 On a bacterial enzyme which specifically decomposes $O$ substance. Proc. Japan. Acad,, 28: 370-373.

IsEKI, S., AND S. MASAKI 1953 Transformation of blood group substance by bacterial enzyme. Proc. Japan. Acad., 29: 460-465.

1955 Chemical actions of $O$ and $A$ specific enzymes on the respective blood group substanees. Gunma. J. Med. Sci., 4: 105-116.

IsEKr, S., AND T. IKEDA 1956 On bacterial enzymes specifically decomposing group B substance. Proc. Japan. Acad., 32: 201-205. 
Satazar Mallen, M. 1951 Estudio immunologico de restos oseos antiguos. Gac. Méd. Méx., 81: 122-127.

ScHIFF, F. 1935 Uber den abbau gruppenspenzifisher substanzen bakterien. Klin. Wochenschrift, 14: 570-571.

1939 An eeto-enzyme of Clostridium welchii which decomposes blood group specific substance A. J. Infect. Dis, 35 : 128-133.

STACK, M. V., AND W. T. J. MoRgan 1949 The preparation and properties of enzymes from Clostridium welchii (type B) filtrates which destroy blood group substances. Brit. J. Exp. Path., 30: 470-483.

Thieme, F. P., C. M. OTTEN AND H. E. SutTon 1956 A blood typing of human skull fragments from the Pleistocene. Am. J. Phys. Anthrop., 14: $437-444$. 